\title{
Questionnaire of chronic illness care in primary care-psychometric properties and test-retest reliability
}

Jost Steinhaeuser ${ }^{*}$, Antje Miksch, Dominik Ose, Katharina Glassen, Iris Natanzon, Joachim Szecsenyi and Katja Goetz

\begin{abstract}
Background: The Chronic Care Model (CCM) is an evidence-based approach to improving the structure of care for chronically ill patients with multimorbidity. The Assessment of Chronic Illness Care (ACIC), an instrument commonly used in international research, includes all aspects of the CCM, but cannot be easily extended to the German context. A new instrument called the "Questionnaire of Chronic Illness Care in Primary Care" (QCPC) was developed for use in Germany for this reason. Here, we present the results of the psychometric properties and test-retest reliability of QCPC.

Methods: A total of 109 family doctors from different German states participated in the validation study. Participating physicians completed the QCPC, which includes items concerning the CCM and practice structure, at baseline (T0) and 3 weeks later (T1). Internal consistency reliability and test-retest reliability were evaluated using Cronbach's alpha and Pearson's r, respectively.

Results: The QCPC contains five elements of the CCM (decision support, delivery system design, self-management support, clinical information systems, and community linkages). All subscales demonstrated moderate internal consistency and moderate test-retest reliability over a three-week interval.

Conclusions: The QCPC is an appropriate instrument to assess the structure of chronic illness care. Unlike the ACIC, the QCPC can be used by health care providers without CCM training. The QCPC can detect the actual state of care as well as areas for improvement of care according to the CCM.
\end{abstract}

Keywords: Multimorbidity, Chronic Care, Health Care Delivery, ACIC, Chronic Care Model

\section{Background}

The number of patients with multiple chronic diseases is growing world-wide [1]. Multimorbidity affects the quality of life, utilization of health care services and mortality [2]. In general practice, multimorbidity is defined as the co-occurrence of two or more chronic conditions [3]. Little is known about the optimal management of patients with multimorbidity and interactions between multiple drugs and diseases within the framework of chronic illness care.

The Chronic Care Model (CCM) is an evidence-based approach to improving care for chronically ill patients

\footnotetext{
* Correspondence: jost.steinhaeuser@med.uni-heidelberg.de

Department of General Practice and Health Services Research, University of Heidelberg, Voßstraße 2, 69115 Heidelberg, Germany
}

with multimorbidity [4]. It was developed in the United States during the 1990s [5]. The Assessment of Chronic Illness Care (ACIC) is internationally used to determine whether and to what extent an implemented system is optimizing the quality of care according to the CCM $[6,7]$.

The ACIC assesses all six elements of the CCM (organization of the healthcare delivery system, decision support, delivery system design, self-management support, clinical information system, and community linkages). To measure how care is provided in German practices, researchers have started to translate-and tried to culturally adapt the ACIC instrument. During this process, we determined that the ACIC is not fully applicable to the German health care system. These limitations are 
due to a multifaceted understanding of terms, different levels of knowledge of the CCM, and fundamental differences between health care systems [8]. The CCM has proven benefits for chronically ill patients [9], and its implementation in primary care seems to be promising [10]. Therefore, a new instrument-the "Questionnaire of Chronic Illness Care in Primary Care" (QCPC)-was created by German researchers to measure the current status of care according to the CCM and potentials for improvement and further development. The QCPC includes the theoretical background of the CCM. Unlike using the $\mathrm{ACIC}$, instrument, a physician in charge of a practice should be able to complete the QCPC without any special training in CCM. Here, we report the results of the psychometric properties and test-retest reliability of the QCPC.

\section{Methods}

In a first step, we collected data on the CCM and factors influencing the care of patients in Germany with multiple chronic conditions based on a literature search and our own hypotheses. The ACIC instrument and questionnaires such as Patient Assessment of Chronic Illness Care (PACIC) [11] and the Commonwealth Fund survey [12] were assessed. Based on the theory behind these questionnaires, new items were developed according to the rule to design a questionnaire study in health care [13]. Additional topics were collected and items drafted in a qualitative process of brainstorming and consensus [8]. Most additions concerned the structure of practices as former research has shown that factors such as practice size rather than chronic care organization determine outcomes [14-16].

Nine general practitioners were asked to evaluate the questionnaire to determine whether each item was understandable, whether the content of an item was important for care of chronically ill patients, and whether any important aspects were missing. Details of this process are published elsewhere [8].

\section{Recruitment}

A total of 288 general practitioners throughout Germany, each of which had participated in the European Practice Assessment for health care quality improvement [17] during the last two years, were invited by fax to participate in the validation study. One hundred nine general practitioners completed the questionnaire at baseline $(\mathrm{T} 0=$ test $)$, and 87 completed it again 3 weeks later $(\mathrm{T} 1=$ retest $)$. Therefore, a total of 87 data sets were available for reliability analysis.

\section{Questionnaire}

The version of the QCPC used in the validation study contained 42 questions concerning care based on the
CCM and 28 questions based on other hypotheses (23 regarding aspects of practice structure, 3 concerning quality management aspects, and 2 concerning disease management programs). The questionnaire is shown in the additional file 1. Five essential elements of the CCM (decision support, delivery system design, self-management support, clinical information systems and community linkages) were handled as subscales and analyzed in detail. Our previous experience has shown that the ACIC domain healthcare delivery system cannot be easily extended to the German context due to fundamental differences between health systems [8]. Therefore we did not included questions about this domain in the QCPC.

The "decision support" subscale consists of two items rated on a five-point Likert scale $(1=$ always to $5=$ never). The "delivery system design" subscale consists of eight items, two of which are rated on a five-point Likert scale $(1=$ always to $5=$ never $)$, and the other six on a different five-point Likert scale $(1=0 \%$ to $5=$ more than $75 \%$ ). The "self-management support" subscale consists of eight items rated on a five-point Likert scale $(1=$ always to $5=$ never $)$. The "clinical information systems" subscale comprises 15 items answered with a " $1=$ yes" or " $2=$ no". The "community linkages" subscale consists of nine items rated on a five-point Likert scale $(1=$ very satisfied to $5=$ very unsatisfied $)$.

\section{Statistical analysis}

All analyses were carried out using SPSS 18.0 software (SPSS Inc., Chicago, IL USA). A hierarchical cluster analysis was performed to identify differences and similarities in the hierarchy structure of the different practices. Internal consistency was assessed using Cronbach's alpha, which indicates whether an item of a scale is appropriate for assessing the underlying concept of the scale [18]. Values for Cronbach's alpha range from 0 to 1 . The closer they are to 0 , the less related the items are to one another. Values above 0.60 are generally considered to indicate satisfactory internal consistency, and those above 0.80 indicate high internal consistency.

Test-retest reliability was assessed using the nonparametric Spearman rank order correlation coefficient $(r)$ to determine the stability of the questionnaire. This criterion refers to the likelihood that a test will yield the same description of a phenomenon if the test is repeated and the phenomenon is unchanged [19]. Retest reliability is defined as correlation between the two test ratings. Spearman rank was computed as recommended in the original study. Spearman rank scores range from -1 to 1 , where a score of 1 indicates the highest correspondence. QCPC items showing $r$ values larger than 0.50 are considered to be very reliable. However, their 
reliability also depends on the expected stability of the investigated construct.

The nonparametric Wilcoxon matched paired test was used to test for differences between T0 and T1. If no significant differences were detected, the stability of the construct could be assumed. The level of significance was $\mathrm{p}<0.05$ respectively $\mathrm{p}<0.01$.

\section{Ethical approval}

The study was fully approved by the ethics committee of the Medical Faculty of the University of Heidelberg (approval number S-090/2009).

\section{Results}

Of 288 practices invited to participate in the validation study, the completed questionnaire was returned by 109 $(38 \%)$ at $\mathrm{T} 0$ and by $87(30 \%)$ at $\mathrm{T} 1$. The characteristics of our study participants are presented in Table 1. Cluster analysis revealed five distinct clusters, one of which contained 75 of the practices. This indicates that there was little overall variation.

Table 2 shows the results for the "decision support" and "delivery system design" subscales. The internal consistency $(\alpha)$ of the "decision support" subscale was determined to be 0.74 . The correlation coefficients used for test-retest reliability were 0.70 and 0.66 , respectively. Matched paired tests showed no significant differences. Internal consistency of the "delivery system design" subscale was 0.45 . The correlation coefficients for test-retest reliability ranged from 0.48 to 0.67 . Significant differences in one item of this subscale ("Are you informed when your patients receive hospital treatment") were detected, as reflected by p-values of 0.03 . There were no significant differences in the other seven items of this subscale.

Table 3 shows the results for the "self-management support" subscale. Internal consistency was for this subscale was 0.63 , and the correlation of single items

\section{Table 1 Characteristics of study participants}

\begin{tabular}{ll}
\hline Female, $\mathrm{n}(\%)$ & $74(67.9)$ \\
\hline Male, $\mathrm{n}(\%)$ & $34(31.2)$ \\
\hline Years of practice experience mean; $\left(\mathrm{SD}^{*}\right)$ & $54.0(7.5)$ \\
\hline Single-handed practice, $\mathrm{n}(\%)$ & $18.56(8.55)$ \\
\hline Group practice, $\mathrm{n}(\%)$ & $57(52.3)$ \\
\hline Inhabitants in practice area & $46(42.1)$ \\
\hline Less than 5,000, $\mathrm{n}(\%)$ & $17(15.6)$ \\
\hline 5,000 to 20,000, $\mathrm{n}(\%)$ & $36(33.0)$ \\
\hline$>20,000$ to $100,000, \mathrm{n}(\%)$ & $20(18.3)$ \\
\hline More than 100,000, $\mathrm{n}(\%)$ & $36(33.0)$ \\
\hline * Standard deviation &
\end{tabular}

ranged from 0.50 to 0.67 . The matched paired test showed in one item a significant differences $(\mathrm{p}=0.02)$ which was called the assessment of drug history.

The results for the "clinical information systems" subscale are presented in Table 4. Internal consistency for this subscale was 0.68 . The correlation values determined as test-retest reliability ranged from 0.29 to 0.98 , and no significant differences between items were found.

Table 5 shows the results for the "community linkages" subscale. Internal consistency was 0.78 , and the correlation coefficients for test-retest reliability ranged from 0.50 to 0.62 . One item of this subscale, "satisfaction with other GP practices", showed a significant differences $(p=0.04)$. No significant differences in the other eight items of this subscale were detected.

Because one item of the "community linkages" subscale ("satisfaction with the exchange of information with other GP practices") was not stable, it was deleted from the questionnaire.

\section{Discussion}

This report describes the results of the psychometric properties and test-retest reliability of the QCPC, which contains elements of the CCM. The results indicate that the QCPC might be the first instrument giving psychometric properties insight into the question of whether and to what degree German practices have already implemented CCM elements into daily care of patients with one or more chronic conditions. The importance of practice structure has been demonstrated in previous research $[16,20]$. Almost two-thirds of our participating practices belong to one cluster and shows that a small inter-practice variability regarding measure of quality of care exists. This is an important aspect for caring patients with chronic conditions at primary care [21]. However, more then one-third of the items on the QCPC relate to aspects of practice structure. The QCPC does not contain items relating to the CCM element "health system/organization of health care" because of its limited applicability in the German context. Knowledge transfer from one country to another has known limitations [22]. Therefore a country specific process has to be intended in any case of knowledge transfer. However, QCPC does contain the other five elements of the CCM (decision support, delivery system design, selfmanagement support, clinical information systems and community linkages). All of these subscales demonstrated moderate internal consistency and moderate test-retest reliability over the three-week test-retest interval.

For "delivery system design" the internal consistency was low. One reason for this result might be that especially reasons for referral are very little reflected in daily practice. Stability, as assessed using the Wilcoxon 
Table 2 Decision support and delivery system design subscale results

\begin{tabular}{|c|c|c|c|c|c|c|}
\hline \multirow[t]{2}{*}{ Use of evidence-based guidelines by patients with:* } & \multirow[t]{2}{*}{$\begin{array}{l}\text { T0 }(n=109) \\
\text { mean (SD) }\end{array}$} & \multirow[t]{2}{*}{$\begin{array}{l}T_{x 1}(n=85) \\
\text { mean }(S D)\end{array}$} & \multirow[t]{2}{*}{$\begin{array}{l}T_{x 2}(n=85) \\
\text { mean (SD) }\end{array}$} & \multirow[t]{2}{*}{$\begin{array}{l}\text { Wilcoxon matched } \\
\text { pair test, } p \text {-value }{ }^{a}\end{array}$} & \multicolumn{2}{|c|}{$\begin{array}{l}\text { Test-retest } \\
\text { reliability: } \\
\text { Spearman } \\
\text { rho }\end{array}$} \\
\hline & & & & & $r$ & p-value ${ }^{b}$ \\
\hline Single diseases & $2.39(0.71)$ & $2.43(0.72)$ & $2.39(0.76)$ & 0.60 & 0.58 & $<0.01$ \\
\hline Multiple diseases & $2.50(0.76)$ & $2.50(0.77)$ & $2.42(0.80)$ & 0.21 & 0.63 & $<0.01$ \\
\hline \multicolumn{7}{|l|}{ Reasons for referral** } \\
\hline Differential diagnostic/therapeutic reasons & $4.03(1.01)$ & $3.99(1.00)$ & $3.79(1.02)$ & 0.09 & 0.53 & $<0.01$ \\
\hline Own feeling of uncertainty & $2.11(0.57)$ & $2.12(0.62)$ & $2.15(0.59)$ & 0.73 & 0.57 & $<0.01$ \\
\hline Request of a specialist & $2.07(0.94)$ & $2.04(0.94)$ & $2.16(0.84)$ & 0.13 & 0.62 & $<0.01$ \\
\hline $\begin{array}{l}\text { Disease management programs or } \\
\text { guidelines }\end{array}$ & $2.23(0.92)$ & $2.22(0.90)$ & $2.30(0.95)$ & 0.52 & 0.48 & $<0.01$ \\
\hline Patient request & $2.79(0.88)$ & $2.84(0.91)$ & $2.78(0.93)$ & 0.49 & 0.62 & $<0.01$ \\
\hline Request by patient's family member & $1.95(0.64)$ & $1.95(0.65)$ & $1.94(0.67)$ & 1.00 & 0.58 & $<0.01$ \\
\hline $\begin{array}{l}\text { Do you know when your patients are being treated or } \\
\text { admitted to hospital? * }\end{array}$ & $2.12(0.60)$ & $2.11(0.64)$ & $2.25(0.62)$ & 0.03 & 0.52 & $<0.01$ \\
\hline $\begin{array}{l}\text { How often does the provisional discharge letter provide all } \\
\text { relevant information needed for continued care?* }\end{array}$ & $2.24(0.61)$ & $2.24(0.65)$ & $2.24(0.55)$ & 1.00 & 0.67 & $<0.01$ \\
\hline
\end{tabular}

* Five-point scale ranging from 1 "always" to 5 "never"

** Five point scale ranging from 1 " $0 \%$ " to 5 "more than $75 \%$ "

${ }^{\text {a }}$ Statistical significance of differences: $\mathrm{P} \leq 0.05 ;{ }^{\mathrm{b}}$ Statistical significance of differences: $\mathrm{P} \leq 0.01$

$T_{x 1}, T_{x 2}$, measurement points for re-test

matched paired test, was very good. Because one item of the "community linkages" subscale was not stable, it was deleted from the questionnaire. A low test-retest reliability was observed for the item "disease management programs or guidelines" ( $r=0.48)$. The implementation of guidelines in German primary care practice is basic yet. Decision making is rather a matter of former individual hospital pathways but evidence [23]. Therefore treatment is due to individual behavior in each reason for encounter and might explain the low reliability score. We also found a low test-retest reliability of two items of the "clinical information systems" subscale;

Table 3 Self-management support

\begin{tabular}{|c|c|c|c|c|c|c|}
\hline Items* & $\begin{array}{l}\text { T0 }(n=109) \\
\text { mean (SD) }\end{array}$ & $\begin{array}{l}T_{x 1}(n=87) \\
\text { mean (SD) }\end{array}$ & $\begin{array}{l}T_{x 2}(n=87) \\
\text { mean (SD) }\end{array}$ & $\begin{array}{l}\text { Wilcoxon } \\
\text { matched pair } \\
\text { test, } p \text {-value }\end{array}$ & $\begin{array}{l}\text { Test } \\
\text { relia } \\
\text { Spea } \\
\text { rho }\end{array}$ & $\begin{array}{l}\text {-retest } \\
\text { bility: } \\
\text { arman }\end{array}$ \\
\hline & & & & & $r$ & $p$-value ${ }^{b}$ \\
\hline $\begin{array}{l}\text { Handout of non individualized information sheets dealing with the } \\
\text { disease on a daily basis and in difficult conditions }\end{array}$ & $3.23(0.94)$ & $3.25(0.95)$ & $3.21(0.89)$ & 0.66 & 0.51 & $<0.01$ \\
\hline $\begin{array}{l}\text { Handout of an individualized treatment plan with information on } \\
\text { how to deal with the disease on an every day basis and in difficult } \\
\text { conditions }\end{array}$ & $2.91(1.12)$ & $3.09(1.10)$ & $2.96(1.04)$ & 0.26 & 0.54 & $<0.01$ \\
\hline $\begin{array}{l}\text { Discussion of care/therapy options with the patients to achieve an } \\
\text { agreed therapy concept }\end{array}$ & $1.69(0.63)$ & $1.71(0.65)$ & $1.79(0.67)$ & 0.23 & 0.56 & $<0.01$ \\
\hline $\begin{array}{l}\text { Assessment of drug history including OTC and prescription drugs } \\
\text { from other physicians }\end{array}$ & $1.49(0.67)$ & $1.49(0.70)$ & $1.64(0.67)$ & 0.02 & 0.63 & $<0.01$ \\
\hline $\begin{array}{l}\text { Usage of specific instruments to calculate individual risks, e.g., for } \\
\text { coronary heart disease }\end{array}$ & $3.62(1.07)$ & $3.67(1.04)$ & $3.67(1.04)$ & 0.89 & 0.62 & $<0.01$ \\
\hline $\begin{array}{l}\text { Handout of a patient-booklets for documentation, e.g., of blood } \\
\text { glucose or pain levels }\end{array}$ & $2.26(0.85)$ & $2.38(0.85)$ & $2.35(0.91)$ & 0.78 & 0.65 & $<0.01$ \\
\hline Handout of guideline information & $3.19(1.02)$ & $3.24(1.04)$ & $3.11(0.90)$ & 0.16 & 0.67 & $<0.01$ \\
\hline Involvement of patient family members, if desired & $1.75(0.77)$ & $1.80(0.80)$ & $1.86(0.80)$ & 0.48 & 0.50 & $<0.01$ \\
\hline
\end{tabular}

* Five-point scale ranging from 1 "always" to 5 "never"

${ }^{\mathrm{a}}$ Statistical significance of differences: $\mathrm{P} \leq 0.05 ;{ }^{\mathrm{b}}$ Statistical significance of differences: $\mathrm{P} \leq 0.01$ 
Table 4 Clinical information systems

\begin{tabular}{|c|c|c|c|c|c|c|}
\hline \multirow[t]{2}{*}{ Items* } & \multirow[t]{2}{*}{$\begin{array}{l}\text { T0 }(n=109) \\
\text { mean }(S D)\end{array}$} & \multirow[t]{2}{*}{$\begin{array}{l}T_{x 1}(n=85) \\
\text { mean }(S D)\end{array}$} & \multirow[t]{2}{*}{$\begin{array}{l}T_{x 2}(n=85) \\
\text { mean }(S D)\end{array}$} & \multirow[t]{2}{*}{$\begin{array}{l}\text { Wilcoxon matched pair test, } \\
\text { p-value }^{a}\end{array}$} & \multicolumn{2}{|c|}{$\begin{array}{l}\text { Test-retest } \\
\text { reliability: } \\
\text { Spearman rho }\end{array}$} \\
\hline & & & & & $r$ & p-value ${ }^{b}$ \\
\hline Access to internet & $1.23(0.42)$ & $1.26(0.44)$ & $1.25(0.43)$ & 0.66 & 0.85 & $<0.01$ \\
\hline E-mail contact with colleagues & $1.33(0.47)$ & $1.34(0.48)$ & $1.37(0.49)$ & 0.48 & 0.77 & $<0.01$ \\
\hline E-mail contact with patients & $1.56(0.50)$ & $1.60(0.49)$ & $1.56(0.50)$ & 0.32 & 0.76 & $<0.01$ \\
\hline Access to medical literature & $1.07(0.25)$ & $1.08(0.28)$ & $1.08(0.28)$ & 1.00 & 0.58 & $<0.01$ \\
\hline Access to guidelines & $1.10(0.30)$ & $1.12(0.33)$ & $1.14(0.35)$ & 0.71 & 0.65 & $<0.01$ \\
\hline Internet homepage & $1.54(0.50)$ & $1.58(0.50)$ & $1.56(0.50)$ & 0.32 & 0.98 & $<0.01$ \\
\hline Brochure with practice information & $1.44(0.50)$ & $1.41(0.50)$ & $1.38(0.52)$ & 0.48 & 0.81 & $<0.01$ \\
\hline Flyer for therapeutic/diagnostic options & $1.36(0.48)$ & $1.27(0.45)$ & $1.27(0.45)$ & 1.00 & 0.66 & $<0.01$ \\
\hline Appointment scheduling & $1.47(0.50)$ & $1.51(0.50)$ & $1.51(0.50)$ & 1.00 & 0.95 & $<0.01$ \\
\hline Documentation/patient records & $1.05(0.21)$ & $1.05(0.23)$ & $1.03(0.16)$ & 0.32 & 0.29 & 0.01 \\
\hline Reminders & $1.26(0.44)$ & $1.25(0.43)$ & $1.26(0.44)$ & 0.74 & 0.70 & $<0.01$ \\
\hline Checking for interactions when prescribing drugs & $1.24(0.43)$ & $1.26(0.44)$ & $1.32(0.47)$ & 0.32 & 0.46 & $<0.01$ \\
\hline Access to data from hospitals & $1.86(0.37)$ & $1.90(0.34)$ & $1.96(0.46)$ & 0.44 & 0.41 & $<0.01$ \\
\hline Screening for patients & $1.19(0.39)$ & $1.21(0.41)$ & $1.19(0.40)$ & 0.74 & 0.61 & $<0.01$ \\
\hline Patient lists with appointments & $1.37(0.48)$ & $1.36(0.48)$ & $1.36(0.48)$ & 1.00 & 0.57 & $<0.01$ \\
\hline
\end{tabular}

* Two-point scale ranging from " 1 " (yes) to " 2 " (no)

${ }^{a}$ Statistical significance of differences: $P \leq 0.05 ;{ }^{b}$ Statistical significance of differences: $P \leq 0.01$

namely, "documentation and patient files" $(\mathrm{r}=0.29)$ and "access to data from hospitals" $(r=0.41)$. Because it currently is not possible to access data directly from German hospitals, we decided to delete that item. Conversely, we decided that "documentation and patient files" was important for German physicians in terms of billing by the German Association of Statutory Health Insurance Physicians. Overall, the results of our study showed moderate to low values for test-retest reliability, which is related to the lower variance of some items
[24]. However results need to be discussed in the light of the low response rate. This might be partly due to little interest in redesigning care and the length of the questionnaire.

\section{Strengths and weaknesses}

The QCPC is a questionnaire for assessment of care according to the CCM with psychometric properties and test-retest reliability. The QCPC can be used in a large number of practices without previous teaching in CCM

Table 5 Community linkages

\begin{tabular}{|c|c|c|c|c|c|c|}
\hline \multirow[t]{2}{*}{$\begin{array}{l}\text { Satisfaction with the exchange of information } \\
\text { with:* }\end{array}$} & \multirow[t]{2}{*}{$\begin{array}{l}\text { T0 }(n=109) \\
\text { mean }(S D)\end{array}$} & \multirow[t]{2}{*}{$\begin{array}{l}T_{x 1}(n=85) \\
\text { mean }(S D)\end{array}$} & \multirow[t]{2}{*}{$\begin{array}{l}T_{x 2}(n=85) \\
\text { mean }(S D)\end{array}$} & \multirow[t]{2}{*}{$\begin{array}{l}\text { Wilcoxon matched pair test, } \\
\text { p-value }^{a}\end{array}$} & \multicolumn{2}{|c|}{$\begin{array}{l}\text { Test-retest } \\
\text { reliability: } \\
\text { Spearman } \\
\text { rho }\end{array}$} \\
\hline & & & & & $r$ & $p$-value ${ }^{b}$ \\
\hline Other GP practices & $2.35(0.94)$ & $2.39(0.98)$ & $2.20(0.95)$ & 0.04 & 0.62 & $<0.01$ \\
\hline Specialist practices & $2.31(0.77)$ & $2.35(0.84)$ & $2.33(0.72)$ & 0.75 & 0.62 & $<0.01$ \\
\hline Psychotherapists & $3.13(0.95)$ & $3.02(0.98)$ & $3.09(1.03)$ & 0.67 & 0.60 & $<0.01$ \\
\hline Physiotherapists/occupational therapists & $2.95(0.83)$ & $2.59(0.82)$ & $2.67(0.89)$ & 0.32 & 0.52 & $<0.01$ \\
\hline Nursing homes & $2.46(0.86)$ & $2.50(0.89)$ & $2.60(0.95)$ & 0.31 & 0.55 & $<0.01$ \\
\hline Medical supply stores & $2.80(0.87)$ & $2.77(0.85)$ & $2.83(0.89)$ & 0.47 & 0.62 & $<0.01$ \\
\hline Pharmacies & $2.14(0.95)$ & $2.09(0.92)$ & $2.13(0.97)$ & 0.75 & 0.59 & $<0.01$ \\
\hline Hospitals & $2.50(0.85)$ & $2.50(0.81)$ & $2.57(0.77)$ & 0.35 & 0.58 & $<0.01$ \\
\hline Rehabilitation facilities & $2.57(0.86)$ & $2.56(0.83)$ & $2.55(0.83)$ & 0.87 & 0.50 & $<0.01$ \\
\hline
\end{tabular}

* Five-point scale ranging from 1 "very satisfied" to 5 "very unsatisfied"

a Statistical significance of differences: $\mathrm{P} \leq 0.05 ;{ }^{\mathrm{b}}$ Statistical significance of differences: $\mathrm{P} \leq 0.01$

$T_{x 1}, T_{x 2}$, measurement points for the re-test 
background. However, the construct of the questionnaire especially different measurement scales in one questionnaire does not allow exploring a factor analysis. To conduct an exploratory or confirmatory factor analysis the measurement scales should be consistent [25]. This specific problem is already known for the PACIC validation [26]. Further methodological research should determine the underlying factor structure through implementation of construct validity. Due to the study design a non-responder characteristic was not determined.

As the QCPC was designed for use by primary care physicians, we were unable to assess different points of view from other practice team members. Another limitation is that the preliminary QCPC results will not be comparable to those of past international studies.

\section{Conclusions}

The QCPC is a questionnaire for assessment of care according to the CCM in Germany which was tested of their psychometric properties. Unlike the ACIC instrument, the QCPC can be used in a high number of practices as the respondents need no prior training in CCM. The QCPC can gauge the current state of care as well as areas for improvement of care. The ESTHER-cohort was the first study performed in the federal state of Saarland, Germany, in which the QCPC was used to survey whether structured care according to the CCM leads to better care of multimorbid (and frail) patients. The ESTHER-cohort includes almost $700 \mathrm{GPs}$ and about 10,000 patients $[27,28]$. Outcome data from this study will make it possible to complete the next validation step.

\section{Additional material}

Additional file 1: The Questionnaire of Chronic Illness Care in

Primary Care (QCPC). English translation of the Questionnaire of Chronic Illness Care in Primary Care (QCPC).

\begin{abstract}
Acknowledgements
We would like to thank the German Federal Ministry of Education and Research for funding the research (grant no. 01 ET 0718, "Health in Old Age").
\end{abstract}

\section{Authors' contributions}

All authors made substantive contributions to the study. JS, AM, DO, KGI, IN, JSz, and KG contributed in producing the QCPC. JS drafted the manuscript and analysed together with KG the data. All authors made contributions to the manuscript. All authors have read and approved the final manuscript.

\section{Competing interests}

The authors declare that they have no competing interests.

Received: 15 October 2010 Accepted: 2 November 2011

Published: 2 November 2011
References

1. Gijsen R, Hoeymans N, Schellevis FG, Ruwaard D, Satariano WA, van den Bos GA: Causes and consequences of comorbidity: a review. J Clin Epidemiol 2001, 54:661-674.

2. WHO chronic disease report. 2010 [http://www.who.int/chp/ chronic_disease_report/contents/en/index.html].

3. vd Akker M, Buntinx F, Metsemakers JF, Roos S, Knottnerus JA: Multimorbidity in general practice: prevalence, incidence and determinants of co-occurring chronic and recurrent diseases. J Clin Epidemiol 1998, 51:367-375.

4. Coleman K, Austin BT, Brach C, Wagner EH: Evidence on the chronic care model in the new millennium. Health Aff 2009, 28:75-85.

5. Wagner E, Austin BT, Von Korff M: Improving outcomes in chronic illness. Manag Care Q 1996, 4:12-25.

6. Bonomi AE, Wagner EH, Glasgow RE, VonKorff M: Assessment of Chronic IIIness Care (ACIC): a practical tool to measure quality improvement. Health Serv Res 2002, 37:791-820.

7. Solberg LI, Crain AL, Sperl-Hillen JM, Hroscikoski MC, Engebretson KI, O'Connor PJ: Care quality and implementation of the chronic care model: a quantitative study. Ann Fam Med 2006, 4:310-316.

8. Steinhaeuser J, Goetz K, Ose D, Glassen K, Natanzon I, Campbell S, Szecsenyi J, Miksch A: Applicability of the Assessment of Chronic Illness Care $(\mathrm{ACI})$ instrument in Germany resulting in a new questionnaire: Questionnaire of Chronic Illness Care in Primary Care. BMC Health Serv Res 2011, 11:164.

9. Bodenheimer T, Wagner EH, Grumbach K: Improving primary care for patients with chronic illness. The Chronic Care Model, Part 2. JAMA 2002, 288:1909-1914.

10. Summaries of the Reports of the Advisory Council on the Assessment of Developments in the Health Care System. Report 2009: Coordination and Integration-Health Care in an Ageing Society 2010 [http://www.Svrgesundheit.de/Startseite/Startseite.htm].

11. Rosemann T, Laux G, Droesemeyer S, Gensichen J, Szecsenyi J: Evaluation of a culturally adapted German version of the Patient Assessment of Chronic Illness Care (PACIC 5A) questionnaire in a sample of osteoarthritis patients. J Eval Clin Pract 2007, 13:806-813.

12. Schoen C, Osborn R, How SK, Doty MM, Peugh J: In chronic condition: experiences of patients with complex health care needs in eight countries 2008. Health Aff 2009, 28:1-16.

13. Sim J, Wright C: Research in health care. Concepts, designs and methods. Nelson Thornes Ltd, Cheltenham; 2002.

14. Wensing M, Van den Hombergh P, Van Doremalen J, Grol R, Szecsenyi J: General practitioners' workload associated to practice size rather than chronic care organisation. Health Policy 2009, 89:124-129.

15. Russell GM, Dahrouge S, Hogg W, Geneau R, Muldoon L, Tuna M: Managing chronic disease in Ontario primary care: the impact of organizational factors. Ann Fam Med 2009, 7:309-318.

16. Zweifler J: The missing link: improving quality with a chronic disease management intervention for the primary care office. Ann Fam Med 2007, 5:453-446.

17. Engels $Y$, Dautzenberg M, Campbell S, Broge B, Boffin N, Marshall M, Elwyn G, Vodopivec-Jamsek V, Gerlach FM, Samuelson M, Grol R: Testing a European set of indicators for the evaluation of the management of primary care practices. Fam Pract 2006, 23:137-147.

18. Cronbach LJ: Coefficient alpha and the internal structure of tests. Psychometrika 1951, 16:297-334.

19. Roussin V, Gasser T, Seifert B: Assessing intrarater, interrater and testretest reliability of continuous measurements. Stat Med 2002, 21:3431-3446.

20. Proudfoot JG, Bubner T, Amoroso C, Swan E, Holton C, Winstanley J, Beilby J, Harris MF: Chronic care team profile: a brief tool to measure the structure and function of chronic care teams in general practice. J Eval Clin Pract 2009, 15:692-698.

21. Proudfoot J, Jayasinghe UW, Infante F, Beilby J, Amoroso C, Powell Davies G, Grimm J, Holton C, Bubner T, Harris M: Quality of chronic disease care in general practice: the development and validation of a provider interview tool. BMC Fam Pract 2007, 8:21.

22. van der Ploeg E, Depla MF, Shekelle P, Rigter H, Mackenbach JP: Developing quality indicators for general practice care for vulnerable elders; transfer from US to The Netherlands. Qual Saf Health Care 2008, 17:291-295. 
23. Kuehlein T, Goetz K, Laux G, Gutscher A, Joos S: Antibiotics in urinary-tract infections. Sustained change in prescribing habits by practice test and self-reflection: a mixed methods before-after study. BMJ Qual Saf 2011.

24. Buehner M: Introduction to item and questionnaire construction. 2 edition. München: Pearson Studium; 2006, [in German].

25. Jöreskog KG: On the estimation of polychoric correlations and their asymptotic covariance matrix. Psychometrika 1994, 59:381-389.

26. Spicer J, Budge C, Carryer J: Taking the PACIC back to basics: the structure of the Patient Assessment of Chronic Illness Care. J Eval Clin Pract 2010.

27. ESTHER. 2010 [http://esther.dkfz.org/esther/index.html].

28. Loew M, Stegmaier C, Ziegler H, Rothenbacher D, Brenner H: ESTHER study. [Epidemiological investigations of the chances of preventing, recognizing early and optimally treating chronic diseases in an elderly population (ESTHER study)]. Dtsch Med Wochenschr 2004, 129:2643-2647, [in German].

\section{Pre-publication history}

The pre-publication history for this paper can be accessed here: http://www.biomedcentral.com/1472-6963/11/295/prepub

doi:10.1186/1472-6963-11-295

Cite this article as: Steinhaeuser et al:: Questionnaire of chronic illness care in primary care-psychometric properties and test-retest reliability. BMC Health Services Research 2011 11:295.

\section{Submit your next manuscript to BioMed Central and take full advantage of:}

- Convenient online submission

- Thorough peer review

- No space constraints or color figure charges

- Immediate publication on acceptance

- Inclusion in PubMed, CAS, Scopus and Google Scholar

- Research which is freely available for redistribution

Submit your manuscript at www.biomedcentral.com/submit 